\title{
Aktivitas Guru Matematika dalam Pembelajaran Menggunakan Perangkat Lunak Geometri Dinamis
}

\author{
Tomi Listiawan* \\ Program Studi Magister Pendidikan Matematika, STKIP PGRI Tulungagung \\ *tomi@stkippgritulungagung.ac.id
}

\begin{abstract}
Abstrak
Penelitian ini bertujuan untuk mendeskripsikan tentang aktivitas pembelajaran guru matematika dalam menggunakan perangkat lunak geometri dinamis (DGS). Penelitian ini merupakan studi kasus dengan subjek penelitian dua orang guru matematika SMP yang melakukan pembelajaran menggunakan DGS. Pengumpulan data dilakukan dengan merekam aktivitas pembelajaran yang dilakukan guru dan wawancara. Data yang telah diperoleh tersebut dianalisis dengan tahapan mentranskrip data, kategorisasi data, mereduksi data, telaah dan analisis data, dan membuat kesimpulan. Hasil penelitian ini menunjukkan bahwa aktivitas yang dilakukan guru dalam menggunakan perangkat lunak geometri dinamis dapat dikelompokkan menjadi: 1) aktivitas peralihan (shifting activity) dan 2) aktivitas penyampaian materi (delivering content activity) yang terbagi menjadi dua bentuk yaitu a) aktivitas menerapkan representasi (applying representation activity) dan b) aktivitas pemodelan (modeling activity). Aktivitas peralihan tampak ketika guru menggunakan DGS dalam jeda aktivitas satu ke aktivitas berikutnya. Aktivitas penyampaian materi-menerapkan representasi tampak ketika guru menggunakan representasi berbasis DGS dengan tujuan untuk mengirimkan pesan (konsep maupun prosedur) dari suatu materi kepada siswa. Aktivitas penyampaian materi-pemodelan tampak ketika guru menggunakan DGS dengan tujuan agar siswa memiliki pengetahuan atau ketrampilan menyelesaikan masalah menggunakan DGS sesuai dengan yang dipraktekkan/ditunjukkan guru. Aktivitas pemodelan dilakukan guru baik secara eksplisit maupun implisit.
\end{abstract}

Kata kunci: aktivitas guru, dynamic geometry software, GeoGebra, perilaku guru

\begin{abstract}
This study aims to describe the use of dynamic geometry software (DGS) by mathematics teachers in their teaching and learning activities. This study case involves two junior high school mathematics teachers who use DGS in their teaching activities. The data of this study were collected by recording teacher activity and interviewing the teachers. The data were then analyzed through data transcription, data categorization, data reduction, data review and analysis, and conclusion. The results of this study involved, first, the use of DGS in teaching and learning activities can be categorized into two activities: 1) shifting and 2) delivering content. The delivering content is later divided into two activities: a) applying representation and b) modeling. Shifting activity occurred when teachers had an interval period while conducting one activity to another. Delivering content-applying representation activity occurred when teachers were using DGS to deliver both conceptual and procedural materials to the students. Delivering content-modeling activity occurred when teachers were using DGS to make students acquire knowledge and have a problem-solving skill as performed by their teachers. The modeling activities occurred either explicitly and implicitly.
\end{abstract}

Keywords: dynamic geometry software, GeoGebra, teachers activities, teachers behavior 


\section{Pendahuluan}

Pembelajaran di dalam kelas terdiri dari rangkaian kegiatan yang dilakukan oleh guru dana siswa. Rangkaian kegiatan tersebut terdiri dari unit-unit aktivitas yang dilakukan oleh guru. Aktivitas guru didefinisikan sebagai segmen dalam kegiatan pembelajaran yang dibatasi oleh (a) fokus dari materi yang disampaikan, (b) bentuk dari kegiatan yang dilaksanakan (Baki \& Arslan, 2016; Doyle, 1983; Yinger, 1986). Doyle menyatakan bahwa aktivitas di dalam kelas biasanya ditandai dengan pengaturan tempat duduk, konten, durasi waktu, alat peraga dan sumberdaya yang digunakan. Dengan kata lain, aktivitas dalam konteks pembelajaran di dalam kelas merupakan berbagai cara untuk mengkomunikasikan informasi, dan menggunakan sumberdaya di dalam kelas.

Ada beberapa aktivitas guru yang terdapat dalam proses pembelajaran, antara lain mengatur alokasi waktu berkenaan dengan berlangsungnya proses pembelajaran, memberikan dorongan kepada siswa agar tumbuh semangat untuk belajar, sehingga minat belajar tumbuh kondusif dalam diri siswa, maupun melaksanakan diskusi dalam kelas. Diskusi adalah wahana yang tepat untuk menciptakan dan menumbuhkan siswa yang kreatif dan produktif serta terlatih berargumentasi secara sehat serta terbiasa menghadapi perbedaan, mengamati siswa. Mengacu pada hasil pengamatan ini guru dapat mengatahui siswa mana yang membutuhkan pembinaan lebih, memberikan informasi lisan maupun tulisan dengan bahasa sederhana dan mudah dimengerti siswa, memberikan masalah untuk dicari solusi pemecahannya, sehingga siswa dapat menggunakan daya pikir dan daya nalarnya secara maksimal, mengajukan pertanyaan dan memberikan respon terhadap pertanyaan yang diajukan siswa, menggunakan media/alat peraga (Gump, 1967; Jamieson-Proctor, Finger, Cavanagh, \& Fitzgerald, 2013).

Aktivitas guru dalam pembelajaran memegang peran penting terhadap keberhasilan proses belajar mengajar di dalam kelas. Hal ini sangatlah beralasan mengingat orkestrasi pembelajaran di dalam kelas, pemegang kendalinya adalah guru. Melihat peran krusial guru dalam melaksanakan aktivitas pembelajaran, banyak peneliti yang mengkaji bagaimana keterkaitan antara aktivitas pembelajaran di dalam kelas dengan proses kognisi yang mendasari terjadinya aktivitas tersebut. Di banyak literatur, bidang ini disebut sebagai penelitian tentang berpikir dan perilaku guru (research on teacher thinking and behavior). Asumsi dasar dalam bidang penelitian ini yaitu tindakan guru secara substansial dipengaruhi dan ditentukan oleh proses berpikir yang dimiliki oleh seorang guru (Clark \& Peterson, 1984). Lebih jauh Clark \& Peterson menjelaskan bahwa secara umum yang dilakukan para peneliti di bidang ini adalah (1) mendeskripsikan secara mendalam tentang proses mental yang terjadi 
pada guru, (2) memahami dan menjelaskan bagaimana dan mengapa bentuk aktivitas guru dapat terjadi.

Terkait dengan hubungan proses berpikir dengan tindakan guru, Clark dan Peterson membuat kerangka kerja untuk memvisualisasikan bagaimana bagian-bagian dari proses berpikir guru berelasi satu dengan yang lain, dan bagaimana penelitian tentang proses berpikir guru melengkapi bagian besar dari penelitian tentang efektivitas pembelajaran. Kerangka kerja tersebut dituangkan dalam model Teacher Thoughts and Action Process (TTAP). Model TTAP dibangun pada dua area yang memainkan peran dalam proses pembelajaran. Pada Gambar 1 tampak bahwa area satu (lingkaran sebelah kiri) adalah proses berpikir guru (teachers thought processess), dan area kedua (lingkaran sebelah kanan) adalah aktivitas atau tindakan guru (teachers' actions and their observable effects). Area satu merupakan daerah yang tak terlihat (unobservable) karena terjadi di dalam struktur kognitif guru, sementara area kedua merupakan daerah yang dapat terlihat (observable) sehingga pengamatan dan penilaian terhadap area kedua lebih mudah untuk dilakukan. Penelitian ini akan mendeskripsikan area kedua dari model TTAP, yaitu aktivitas pembelajaran yang dilakukan guru dalam pembelajaran matematika.

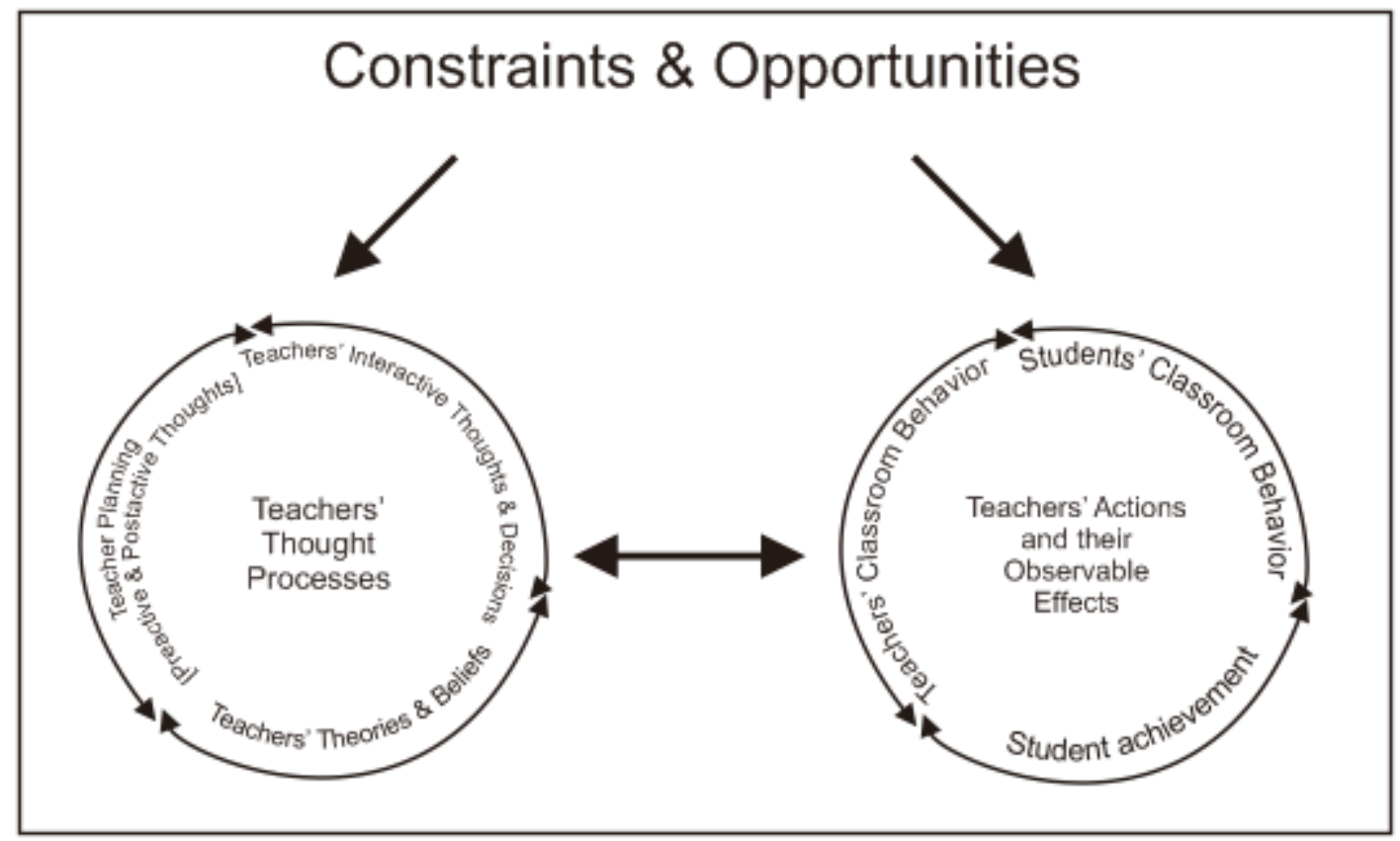

Gambar 1. Model TTAP

Sumber: Clark \& Peterson (1984)

Sebagai perangkat lunak yang memiliki kegunaan khusus dalam menyelesaikan masalah-masalah matematika (mathematical software tool) dan cognitive technological tool, perangkat lunak geometri dinamis (DGS) dapat dimanfaatkan dalam berbagai aktivitas 
pembelajaran (Listiawan \& Baskoro, 2015). M. Hohenwarter dan Fuchs (2004) menyatakan bahwa perangkat lunak geometri dinamis sangat bermanfaat sebagai media pembelajaran matematika dengan beragam aktivitas misalnya sebagai media demonstrasi dan visualisasi. Dalam hal ini, pada pembelajaran yang bersifat tradisional, guru memanfaatkan perangkat lunak geometri dinamis untuk mendemonstrasikan dan memvisualisasikan konsep-konsep matematika tertentu. Disisi lain perangkat lunak geometri dinamis juga dapat digunakan sebagai alat bantu konstruksi (Listiawan, 2017; Listiawan \& Baskoro, 2015). Dalam hal ini perangkat lunak geometri dinamis digunakan untuk memvisualisasikan konstruksi konsep matematika tertentu, misalnya mengkonstruksi lingkaran dalam maupun lingkaran luar segitiga, atau garis singgung (Listiawan, Purwanto, As'Ari, \& Muksar, 2018). Selain itu perangkat lunak geometri dinamis juga dapat digunakan sebagai alat bantu proses penemuan. Dalam hal ini perangkat lunak geometri dinamis digunakan sebagai alat bantu bagi siswa untuk menemukan suatu konsep matematis, misalnya tempat kedudukan titik-titik atau karakteristik grafik parabola.

Berdasarkan uraian di atas, tidak banyak peneliti yang berfokus kepada bagaimana bentik aktivitas yang dilakukan guru ketika melakukan pembelajaran menggunakan perangkat lunak geometri dinamis, dan mengapa aktivitas tersebut terjadi. Tujuan artikel ini adalah mendeskripsikan bentuk aktivitas yang dilakukan guru ketika melakukan pembelajaran menggunakan perangkat lunak geometri dinamis, yang merupakan area kedua dari model TTAP Clark dan Peterson.

\section{Metode}

Pendekatan penelitian yang digunakan adalah penelitian ini adalah penelitian kualitatif dengan jenis studi kasus, dengan menyajikan analisis tentang bagaimana aktivitas guru matematika dalam melaksanakan pembelajaran menggunakan perangkat lunak geometri dinamis. Subjek dalam penelitian ini adalah dua orang guru matematika SMP yang menggunakan DGS dalam pembelajarannya. Pemilihan subjek menggunakan teknik purposive yaitu pemilihan subjek dengan tujuan untuk mendapatkan subjek guru matematika yang secara konsisten menggunakan DGS dalam kegiatan pembelajarannya.

Untuk mendapatkan subjek guru matematika SMP yang memiliki kompetensi dalam penggunaan teknologi khususnya DGS, peneliti melakukan komunikasi dengan ketua MGMP SMP Kabupaten Tulungagung. Berdasarkan hasil komunikasi tersebut, peneliti dengan dibantu ketua MGMP menyebarkan angket tentang identifikasi TPACK guru matematika kepada 37 guru matematika SMP di wilayah Kabupaten Tulungagung. Berdasarkan hasil 
angket, dapat diidentifikasi empat guru yang menyatakan menggunakan DGS dalam pembelajarannya. Selanjutya, dari empat guru tersebut, peneliti melakukan observasi dan wawancara untuk melihat konsistensi dalam penggunaan DGS di dalam pembelajarannya.

Konsistensi penggunaan DGS di dalam pembelajaran, ditentukan berdasarkan frekuensi penggunaan DGS (paling sering), dan keajegan dalam pemanfaatannya, yang berarti ketika karakteristik materi yang disampaikan memungkinkan untuk menggunakan DGS, subjek juga menggunakannya. Konsistensi ini dilihat oleh peneliti berdasarkan hasil observasi dan wawancara dengan subjek. Berdasarkan hasil observasi dan wawancara, peneliti menentukan dua subjek yang paling konsisten dalam penggunaan DGS. Penetapan subjek penelitian berdasarkan konsistensi penggunaan DGS ini, dilakukan karena fokus yang dikaji dalam penelitian ini adalah aktivitas guru dalam menggunakan DGS. Subjek yang paling konsisten dalam menggunakan DGS diharapkan dapat memberikan gambaran yang lebih lengkap tentang jawaban dari permasalahan yang ditetapkan dalam penelitian ini.

Pada penelitian ini, data yang dihasilkan terdiri dari 3 (tiga) level. Level pertama adalah data video rekaman pembelajaran yang dilakukan subjek, level kedua adalah data fragmen video aktivitas pembelajaran menggunakan DGS, dan level ketiga adalah data hasil transkrip video pembelajaran dan wawancara. Proses analisis data meliputi: reduksi data, kategorisasi data, sintesis, dan diakhiri dengan penyajian deskripsi hasil analisis.

\section{Hasil Penelitian}

Berdasarkan analisis yang telah dilakukan, peneliti menemukan ada 4 fragmen aktivitas subjek dalam menggunakan DGS dengan bentuk kegiatan membuat representasi untuk mempersiapkan penjelasan aktivitas selanjutnya. Representasi menggunakan DGS ini digunakan subjek untuk memperjelas jawaban permasalahan yang diberikan dalam penugasan sebelumnya, atau menyiapkan representasi untuk bahan penjelasan materi selanjutnya. Aktivitas ini merupakan bentuk aktivitas peralihan (shifting activity), yang secara total dilaksanakan subjek dalam durasi waktu 7,7 menit. 

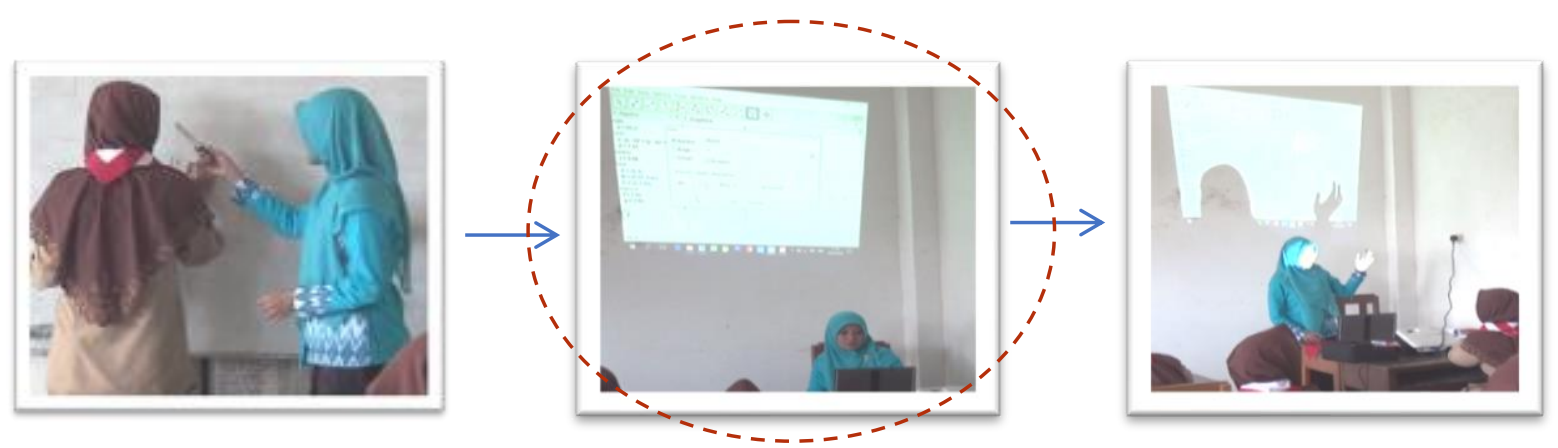

Gambar 2. Aktivitas Peralihan

Selain itu, peneliti juga menemukan 14 fragmen aktivitas pembelajaran menggunakan DGS dengan bentuk kegiatan melakukan penyampaian konten pembelajaran atau materi baik berupa konsep, prosedur, ataupun yang lain. Bentuk kegiatan dari aktivitas ini berbagai macam dengan berbagai metode dan strategi seperti menjelaskan, bertanya, memberikan penugasan, dan lain sebagainya. Ke-empat belas fragmen aktivitas penyampaian materi tersebut memiliki kesamaan karakteristik yaitu memanfaatkan atau menerapkan representasi yang terdapat dalam DGS. Aktivitas ini merupakan bentuk aktivitas menerapkan representasi (applying representation activity) yang dilakukan subjek dalam durasi waktu 39,59 menit.
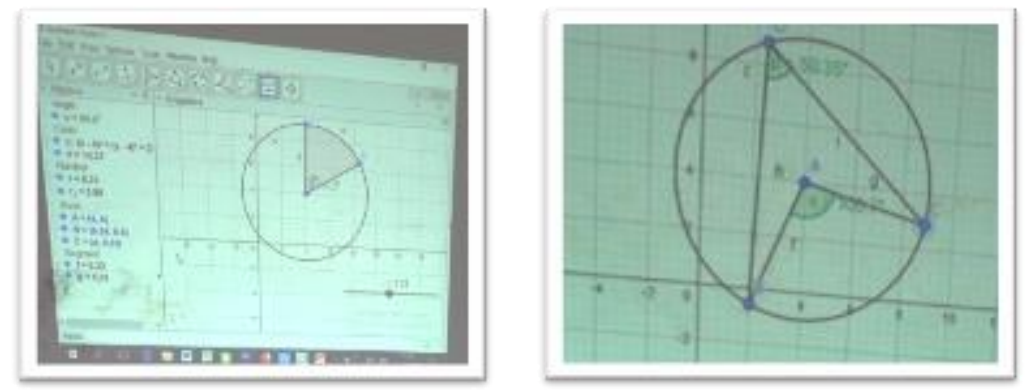

Gambar 3. Aktivitas Menerapkan Representasi

Selain ke 14 fragmen aktivitas penyampaian materi dengan memanfaatkan representasi, terdapat 2 (dua) fragmen penyampaian materi dengan bentuk subjek meminta siswa mengikuti prosedur pembuatan representasi. Prosedur yang dilakukan guru menjadi model dalam aktivitas yang dilakukan oleh siswa. Aktivitas ini merupakan bentuk dari aktivitas pemodelan (modeling activity), yang dilakukan subjek dalam durasi waktu 11,53 menit.
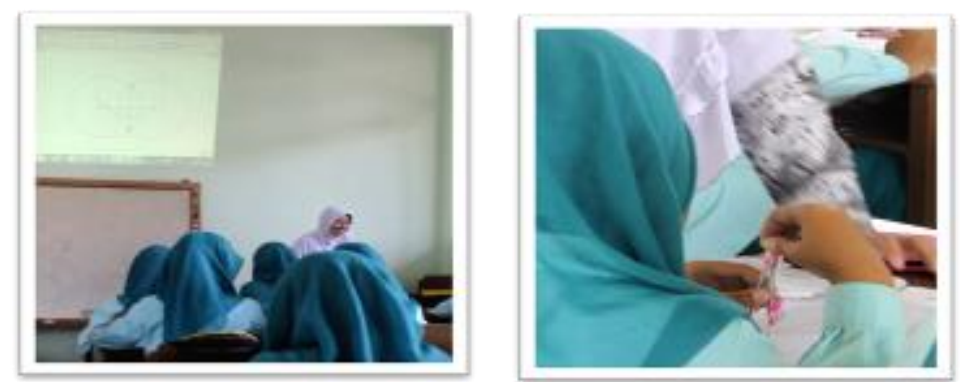

Gambar 3. Aktivitas Pemodelan. 


\section{Pembahasan}

Aktivitas peralihan, merupakan aktivitas guru yang dilakukan di saat jeda dari aktivitas satu ke aktivitas berikutnya. Dalam penelitian terkait aktivitas atau perilaku guru di dalam kelas, aktivitas peralihan bukan merupakan konsep baru. (Arlin, 1979) mengungkapkan dengan istilah "transitions activities" merujuk pada aktivitas ketika guru mengakhiri satu aktivitas dan akan memulai aktivitas berikutnya. Sementara itu Smith (2009) menyebutkan bahwa transitions activities merupakan fase transisi yang menghubungkan antara satu unit atau segmen pembelajaran dengan unit atau segmen yang lain. Secara umum, pada fase peralihan, guru melakukan aktivitas lebih sedikit dibandingkan dengan aktivitas pembelajaran yang lain, namun pada fase peralihan ini guru banyak yang menggunakannya untuk aktivitas yang tidak produktif (Gump, 1967; Smith, 2009), bahkan mengganggu (Arlin, 1979).

Pada fragmen aktivitas peralihan ini, subjek membuat representasi tentang konsep luas juring lingkaran menggunakan DGS. Representasi ini dibuat untuk membandingkan dan memastikan jawaban siswa tentang tugas menghitung luas juring lingkaran yang telah dilaksanakan sebelumnya. Aktivitas peralihan membuat representasi ini merupakan aktivitas yang dilakukan oleh subjek sebagai persiapan untuk melakukan aktivitas berikutnya yaitu membuat kesimpulan tentang prosedur menghitung luas juring lingkaran. Aktvitas peralihan menggunakan DGS dalam penelitian ini sejalan dengan yang dikemukakan oleh Arlin (1979), bahwa salah satu bentuk aktivitas peralihan dalam penelitiannya adalah advance preparation, yang merupakan persiapan guru untuk melakukan aktivitas pembelajaran selanjutnya.

Dalam transkrip pembelajaran yang diperoleh, subjek memberikan penjelasan alternatif penyelesaian masalah menggunakan DGS sehingga siswa dapat membandingkan hasil dari perhitungan menggunakan software ini dengan perhitungan secara manual. Subjek berpendapat bahwa dengan membuat tampilan di geogebra, tampilan objek geometri dapat dijelaskan dengan lebih detail. Hal ini sejalan dengan yang disampaikan Zacharia (2005) bahwa ketika guru berinteraksi dengan computer-based simulations, penjelasan yang dikonstruksi guru menjadi lebih detail, akurat, dan memuat lebih banyak penalaran formal.

Aktivitas penyampaian materi-pemodelan, merupakan aktivitas guru dalam menggunakan DGS dengan tujuan agar siswa memiliki pengetahuan atau ketrampilan menyelesaikan masalah menggunakan DGS sesuai dengan yang dipraktekkan/ditunjukkan guru. Ketika seseorang secara sadar menunjukkan perilaku tertentu dengan harapan bahwa itu akan ditiru, tindakan itu disebut sebagai modeling (Haston, 2007). Penelitian yang dilakukan oleh Bandura (1969), telah mendukung hipotesisnya bahwa perilaku seseorang dapat diperkuat, 
diperlemah, atau dipelihara oleh pemodelan perilaku orang lain. Ketika seseorang meniru perilaku orang lain, maka pemodelan telah terjadi.

\section{Simpulan}

Aktivitas peralihan (shifting activity) terjadi ketika subjek menggunakan DGS dalam jeda aktivitas satu ke aktivitas berikutnya. Dalam aktivitas ini, subjek membuat representasi geometri yang digunakan untuk menjawab penugasan yang diberikan sebelumnya. Selain itu, representasi yang dibuat dalam aktivitas peralihan juga digunakan sebagai bahan untuk menjelaskan pada aktivitas selanjutnya.

Aktivitas penyampaian materi (delivering content activity) dilaksanakan ketika subjek menggunakan DGS dengan tujuan untuk mengirimkan pesan (konsep maupun prosedur) dari suatu materi/konten kepada siswa. Aktivitas ini terbagi ke dalam dua bentuk yang terdiri dari Aktivitas menerapkan representasi (applying representation activity) dan aktivitas pemodelan (modeling activity). Aktivitas menerapkan representasi (applying representation activity) terjadi ketika subjek membuat atau menggunakan representasi untuk menanamkan konsep atau prosedur kepada siswa. Dalam aktivitas ini, representasi diterapkan subjek dalam berbagai kegiatan yaitu menjelaskan, bertanya, penugasan, maupun penunjang dalam kegiatan kelompok. Dalam aktivitas subjek dalam menggunakan DGS, aktivitas menerapkan representasi ini mendominasi dengan jumlah fragmen terbanyak dan waktu yang paling lama. Aktivitas pemodelan (modeling activity) terjadi ketika subjek menggunakan DGS dengan tujuan agar siswa memiliki pengetahuan atau ketrampilan menyelesaikan masalah menggunakan DGS sesuai dengan yang dipraktekkan/ditunjukkan subjek. Aktivitas pemodelan dilakukan oleh subjek secara eksplisit maupun implisit. Pemodelan secara eksplisit ditunjukkan subjek dengan meminta siswa untuk mengikuti prosedur yang dilakukan oleh subjek. Sementara pemodelan secara implisit dilakukan oleh subjek dengan menunjukkan secara detail langkah-langkah pembuatan representasi menggunakan DGS dengan tujuan agar siswa memiliki pengetahuan tentang penggunaan DGS, namun tidak meminta siswa untuk mengikuti prosedur yang dilakukan secara langsung

\section{Referensi}

Arlin, M. (1979). Teacher transitions can disrupt time flow in classrooms. American Educ.O.Ll.Ational Research Journal, $16(1), \quad$ 42-56. https://doi.org/10.3102/00028312016001042.

Baki, M., \& Arslan, S. (2016). Reflections from pre-service teachers mathematics teaching process. H. U. Journal of Education, 31(4), 736-749. https://doi.org/10.16986/HUJE.2015014664. 
Bandura, A. (1969). Social learning theory of identificatory processes. In David A Goslin (Ed.), Handbook of Socialization Theory and Research. Rand McNally \& Company.

Clark, C. M., \& Peterson, P. L. (1984). Teachers' thought processes, (72). Institute for Research on Teaching, College of Education, Michigan State University.

Doyle, W. (1983). Managing classroom activities in junior high English classes: An interim report. (Research and Development Center for Teacher Education, Ed.). University of Texas.

Gump, P. V. (1967). The classroom behavior setting: its nature and relation to student behavior office of education. Kansas: Lawrence, KS: University of Kansas, Department of Psychology.

Haston, W. (2007). Teacher modeling as an effective teaching strategy. Music Educators Journal, 93(4), 26-30. https://doi.org/10.1177/002743210709300414.

Hohenwarter, M., \& Fuchs, K. (2004). Combination of dynamic geometry , algebra and calculus in the software system GeoGebra. Computer Algebra Systems and Dynamic Geometry Systems in Mathematics Teaching Conference 2004, (July), 1-6.

Jamieson-Proctor, Finger, G., Cavanagh, R., \& Fitzgerald, R. (2013). Development of the TTF TPACK survey instrument introduction - The TTF Project and TPACK. Australian Educational Computing, 27(3), 26-35.

Listiawan, T. (2017). Representasi mental dan proses kognitif yang mendasari Technological Pedagogical and Content Knowledge (TPACK). In Seminar Nasional Pendidik dan Pengembang Pendidikan IKIP Mataram 2017 (pp. 588-596). https://doi.org/10.31227/osf.io/p7ny4.

Listiawan, T., \& Baskoro, W. W. (2015). Analisis Technological Content Knowledge (TCK) calon guru matematika dalam menggunakan perangkat lunak geometri dinamis. In Seminar Nasional Matematika dan Pendidikan Matematika 2015 (pp. 827-834). https://doi.org/10.13140/RG.2.1.4443.3522.

Listiawan, T., Purwanto, P., As'Ari, A. R., \& Muksar, M. (2018). Mathematics teachers Technological Content Knowledge (TCK) in using Dynamic Geometry Software. Journal of Physics: Conference Series, 1114, 012121. https://doi.org/10.1088/17426596/1114/1/012121.

Smith, H. A. (2009). The marking of transitions by more and less effective teachers. Theory Into Practice, 24(1), 57-62. https://doi.org/10.1080/00405848509543147.

Yinger, R. J. (1986). Examining thought in action: A theoretical and methodological critique of research on interactive teaching. Teaching and Teacher Education, 2(3), 263-282. https://doi.org/10.1016/S0742-051X(86)80007-5.

Zacharia, Z. C. (2005). The impact of interactive computer simulations on the nature and quality of postgraduate science teachers' explanations in physics the impact of interactive computer simulations on the nature and quality of postgraduate science teachers' explanations. International Journal of Science Education, 27(14), 1741-1767. https://doi.org/10.1080/09500690500239664. 